\title{
Influence of Partial Solar Eclipse on The Radio Signal during 9 March 2016
}

\author{
Nur Zulaikha Mohd Afandi", Roslan Umar", Zainol Abidin Ibrahim*, Nor Hazmin Sabri\%, Marhamah \\ Mohd Shafie \\ ${ }^{\#}$ East Coast Environmental Research Institute, Universiti Sultan Zainal Abidin, 21300 Kuala Nerus, Terengganu, Malaysia \\ E-mail: zulaikhafendy@yahoo.com.my; roslan@unisza.edu.my; marhamah92@yahoo.com \\ *Department of Physics, University of Malaya, 50603 Kuala Lumpur, Malaysia \\ E-mail:drzai@um.edu.my \\ ${ }^{\%}$ School of Fundamental Science, Universiti Malaysia Terengganu, 21030 Terengganu, Malaysia \\ E-mail: norhazmin@umt.edu.my
}

\begin{abstract}
The occasion of the partial solar eclipse in Malaysia occurred on 9th March 2016 covered almost $67 \%$ to $80 \%$ of the whole Sun. During the maximum time of the partial solar eclipse, some of the solar emission and sunlight was blocked to reach the Earth's surface. In order to see this effect to a radio signal, the analysis of radio signal pattern before and during the solar eclipse at Balai Cerap KUSZA, Merang, Terengganu was done. The radio signal measurement was taken in the wideband frequency region from $0 \mathrm{~Hz}$ to $9 \mathrm{GHz}$. The radio signal data had been analysis to compare between before and during the eclipse by calculating their average. Initial analysis shows that there a different number of peak signal between two observations. Then, the solar radiation data during the partial solar eclipse also was analysed. Furthermore, solar events data from National Oceanic and Atmospheric Administration (NOAA) also added into this work. It shows that there not enough prove that the partial solar eclipse affects the radio signal pattern.
\end{abstract}

Keywords - partial solar eclipse; radio signal pattern; solar radiation; solar event

\section{INTRODUCTION}

Sun constantly emits the radiation, charged particles, and light through all its surroundings. It comes from the activities on the surface of sun resulted from the nuclear reaction between gas helium and hydrogen. This red giant dwarf also generates heat towards nearby planets. Besides that, the high kinetic particles also produce and able to penetrate the Earth ionosphere caused by solar flares and Coronal Mass Ejections (CMEs) [1]. Phenomenon such as solar eclipse gave the unique possibility of studying the physical and chemical effects. This is because a nighttime condition and a shadow were formed when the Moon covers only the central parts of the Sun. It is blocking the sunshine and look like a ring on the Sun as Fig. 1. But, in [2] was claimed that the solar eclipse observation gives a scientific valuable to the solar photographer. On 9th March 2016, Asian, Australia, and the Pacific Ocean have experienced the solar eclipse with can totally observe at Sumatra, Sulawesi, Borneo, and Pacific. While, a partial solar eclipse phases can be observed in Malaysia, Borneo and some of the Indonesia as a path on Fig. 2. The eclipse had a magnitude of 1.0450 and gamma of 0.2609. Thus, Moon's shadow starting appeared on northern latitudes of Earth surface. The total eclipse maximal time was 4 minutes 9 second at 0158 UTC near the Pacific Ocean. This phenomenon is one of the total solar eclipses of Saros series 130 (a period equal to 1298.17 years). It occurs at the Moon's descending node by the Moon moves northward. In Malaysia, the duration partial solar eclipse can be seen about one hour five minutes. The percentages of the sun covered and time of a solar eclipse of Peninsular Malaysia can see as Table 1. Johor Bharu is the best location for maximum partial solar eclipse in Malaysia with coverage of $86 \%$. This solar eclipse rarely happened in Malaysia because the last time a partial solar eclipse can see in January 2010. It was a great opportunity to astrophotography and people to capture this moment. This phenomenon has become one of the awaited events for the amateur group and professional agencies in the world. In Malaysia, many locations had been set up as the partial solar eclipse observation for citizen and solar researcher. 
Fig. 1 The totality of solar eclipse on March 9, 2016 at Ternate, Indonesia (Credit to Muhammad Redzuan Tahar, National Space Agency in [3]

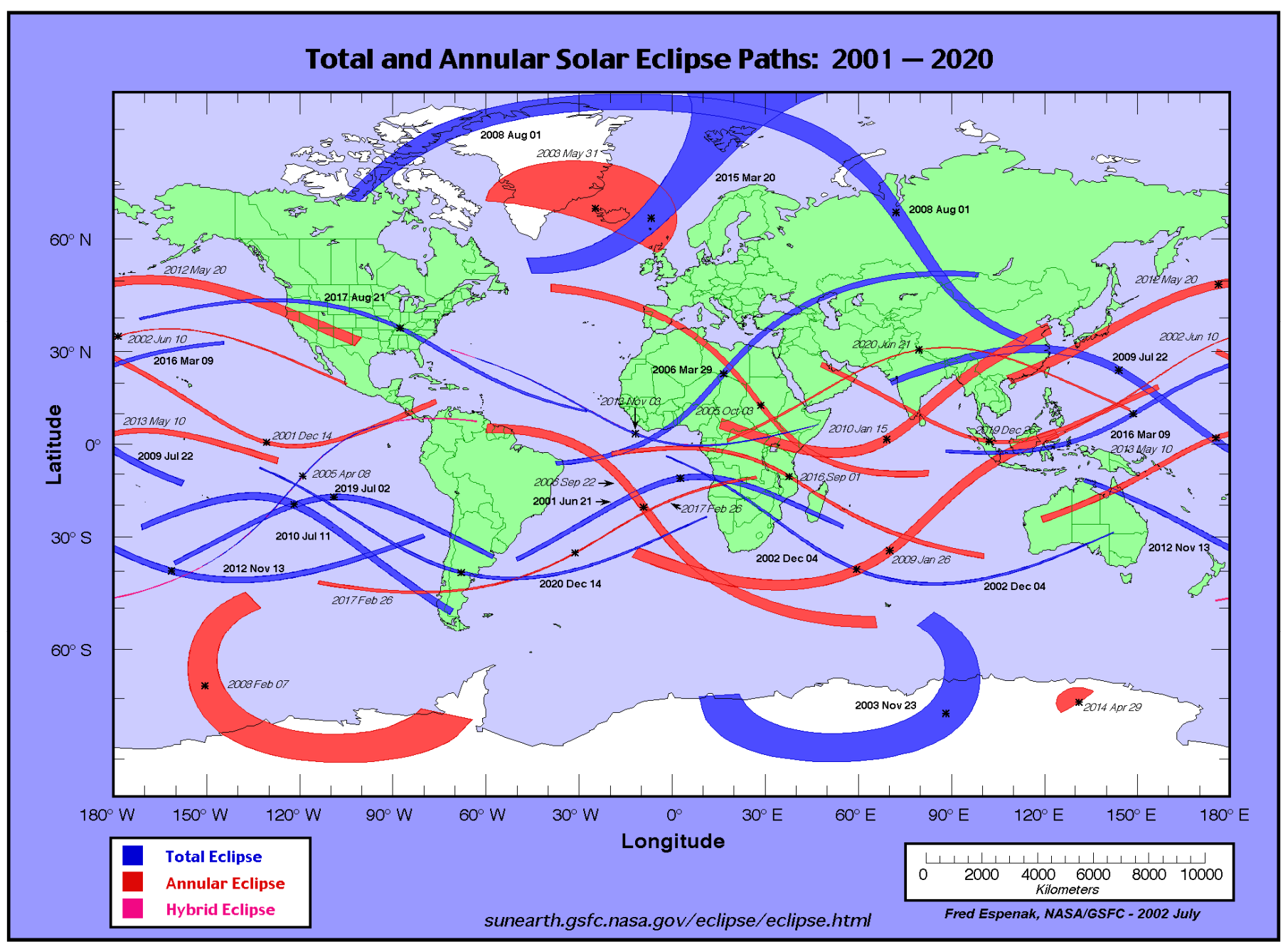

Fig. 2 Paths of total, annular and hybrid of solar eclipse from 2001 until 2020 (Credit to NOAA, SWPC) 
TABLE I

THE DESCRIPTION OF PARTIAL SOLAR ECLIPSE ON $9^{\mathrm{TH}}$ MARCH 2016 AT PENINSULAR MALAYSIA

\begin{tabular}{|l|l|l|l|l|}
\hline \multirow{2}{*}{ Location } & \multirow{2}{*}{$\begin{array}{l}\text { Percent of the } \\
\text { Sun Covered }\end{array}$} & \multicolumn{3}{|c|}{$\begin{array}{l}\text { Partial Solar Eclipse } \\
\text { Time (Hour: Minute) }\end{array}$} \\
\cline { 3 - 5 } & $(\mathbf{\%})$ & Start & Mid & End \\
\hline Kangar & 67 & $7: 31$ & 8.25 & $9: 30$ \\
\hline Alor Setar & 68 & $7: 30$ & 8.25 & $9: 30$ \\
\hline Georgetown & 70 & $7: 30$ & 8.25 & $9: 30$ \\
\hline Ipoh & 73 & $7: 27$ & 8.24 & $9: 30$ \\
\hline Kuala Lumpur & 79 & $7: 24$ & 8.24 & $9: 30$ \\
\hline Seremban & 81 & $7: 23$ & 8.24 & $9: 30$ \\
\hline Melaka & 83 & $7: 23$ & 8.23 & $9: 31$ \\
\hline Johor Bharu & 86 & $7: 23$ & 8.24 & $9: 32$ \\
\hline Kuantan & 77 & $7: 25$ & 8.25 & $9: 33$ \\
\hline *Kuala Terengganu & 71 & $7: 26$ & 8.26 & $9: 33$ \\
\hline Kota Bharu & 68 & 8.26 & 8.26 & $9: 32$ \\
\hline
\end{tabular}

*site study

Generally, observations of the Sun was important to discover a variety of study such as the study of the mechanism of energy transfer, physical characteristics of layers on the sun [4] and effects the Earth atmosphere [5]. And mostly monitoring of Sun is observed at radio wavelength. This is because sun radiation is one of the natural radio frequency sources and able to detect by radio spectrometer at ground. As we know, during a solar eclipse the sunshine was blocking to reach the Earth. Therefore, this project is to study the effects of the partial solar eclipse to radio frequency interference (RFI) pattern. It was called as RFI when any disruption created from natural sources or man-made that affects it. There are past investigations reported by [6] and [7] found that two significance effects during a solar eclipse were signal frequency and path length. This RFI survey must be done for radio astronomical purposes in order to know the quality signal of the Sun. So, it is significant to identify and continuously monitor the unwanted signals emitted from surroundings. Obviously, radio frequency signal is related to sun activities. Therefore, data of solar x-ray flux and an active region (AR) from the missions of the National Oceanic and Atmospheric Administration (NOAA) during the solar eclipse was used for make justification of their effects. An example, a total solar eclipse occurred on 14th November 2012 shows the relation when the formation group of solar radio burst type III is increasing with the eruption of the active region [8]. The eruption of the active region on the corona brings out a strong energy that able to drive to solar flares and coronal mass ejections (CMEs).

The decreasing of sunlight reaching the Earth's surface was the most obvious effect of the total solar eclipse. For example, in [9] report that a large temperature drop by $5^{\circ} \mathrm{C}$ during total solar eclipse occurred on 21st June 2001 over Mana Pools, northern Zimbabwe $\left(15^{\circ} \mathrm{S}\right)$. Another solar eclipse with cloud effect stated by [10], the solar radiation drop $1.5^{\circ} \mathrm{C}$ during 11th August 1999 with 97\% Moon covered the Sun. These effects were an indicator of the physical changes during a solar eclipse. As known, sunlight can convert into the energy and provide a life to the Earth. The amount of sunlight for each country was different depending on latitude and seasons. Malaysia which is Asian country locates at equator receive the sunlight about 12 hours. Thus, the comparisons between solar radiations in different partial solar eclipse phase are investigated in order to know their effect.

\section{MATERIAL AND METHOD}

There three measurements in order to investigate the effect of partial solar eclipse occurred in Malaysia on 9th March 2016. Firstly, the RFI measurement has been done at Balai Cerap KUSZA, Merang. This location is selected due to the clearest location to view a solar eclipse at Terengganu. It is one of the astronomical observations in Terengganu with possible low RFI. The measurement has been done in two different times, which are before and during the solar eclipse. In order to optimize the accuracy and continues RFI, two hour time intervals are taken. The measuring system is contained the copper disconne antenna, Low Noise Amplifier (LNA) and $9 \mathrm{GHz}$ spectrum analyzer (Keysight N9915A) with $180 \mathrm{kHz}$ resolution bandwidth. The data will be transferred to a computer for analysis. Fig. 3 illustrated the RFI connection setup.

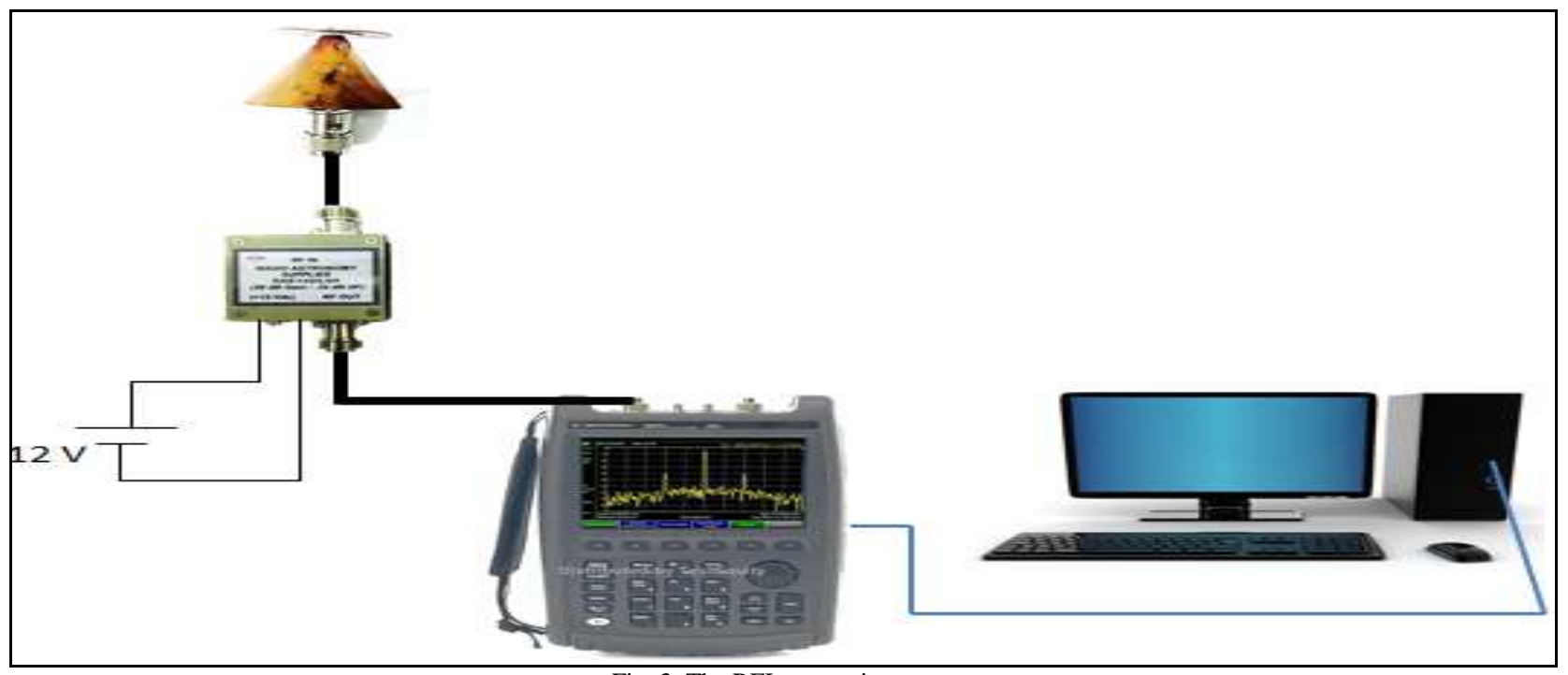

Fig. 3 The RFI connection setup 
The detailed description of the observation is shown in Table 2 . The radio signal measured by spectrum analyzer was averaging. Then, it was plotted into a graph of power level against wide frequency $(0-3 \mathrm{GHz})$ into two different time observations. All the value of power levels was precious averaging from data measured in every second. Then, the solar radiation data was collect from Weather Station at Balai Cerap KUSZA, Merang. The solar radiation values from the start until the end of the partial solar eclipse were used to compare. All the data were transfer into the computer for analysis and documentation.

TABLE III

THE DESCRIPTION OF THE PARTIAL SOLAR ECLIPSE OBSERVATION

\begin{tabular}{|l|l|l|l|}
\hline Description & Date & Start Time & End Time \\
\hline Before & 8 March 2016 & $11: 05 \mathrm{am}$ & $1: 05 \mathrm{pm}$ \\
\hline During & 9 March 2016 & $7: 26 \mathrm{am}$ & $9: 26 \mathrm{am}$ \\
\hline
\end{tabular}

For comparison, the solar activities and solar eclipse, data x-ray flux from GOES mission and image of Sun from SDO mission are collected from NOAA website. This data are collected on the same date of the solar eclipse.

\section{RESULTS AND DISCUSSION}

The full, partial solar eclipse on 9th March 2016 at Balai Cerap Kusza, Merang was recorded by a staff of East Coast Environmental Research Institute (ESERI) as shown in Fig. 4. It has been starting recorded from 07:35 am until 09:29 am at the local time. About $71 \%$ the Moon covered the Sun with maximum partial solar eclipse occurred in less than 5 minutes.

\section{A. RFI Monitoring}

The average of power levels from 0 until $3 \mathrm{GHz}$ for two different time observation with two hours duration were determined and plotted as Fig. 5. The baseline for each observation also was illustrated in the graph.

As shown, a grey and red line of the graph is observed before and during the solar eclipse respectively. It clearly stated that the average of RFI before the solar eclipse is $171.14 \mathrm{dBm}$, while $-156.62 \mathrm{dBm}$ during a solar eclipse. The difference value between two baselines is about $14.52 \mathrm{dBm}$ is considered as a large gap. Then, all peak signals between before and during the solar eclipse have been observed and determined as in Table 3 and 4. Generally, all detected prominence peak have been allocated to man-made sources according to International Telecommunication Union (ITU) and Spectrum Allocation List by Malaysian Communication and Multimedia Commission (MCMC).

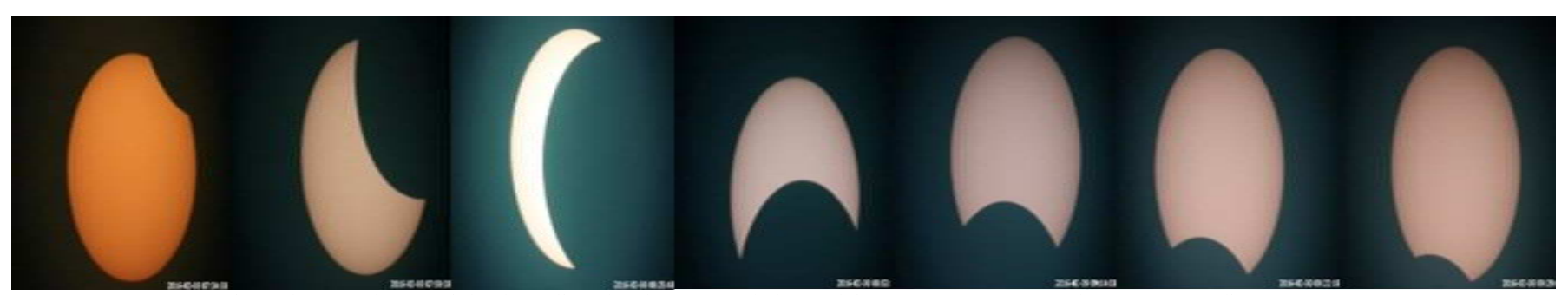

Fig 4. the complete partial solar eclipse has been recorded at Balai Cerap Kusza on March 9, 2016 (Credit to ESERI)

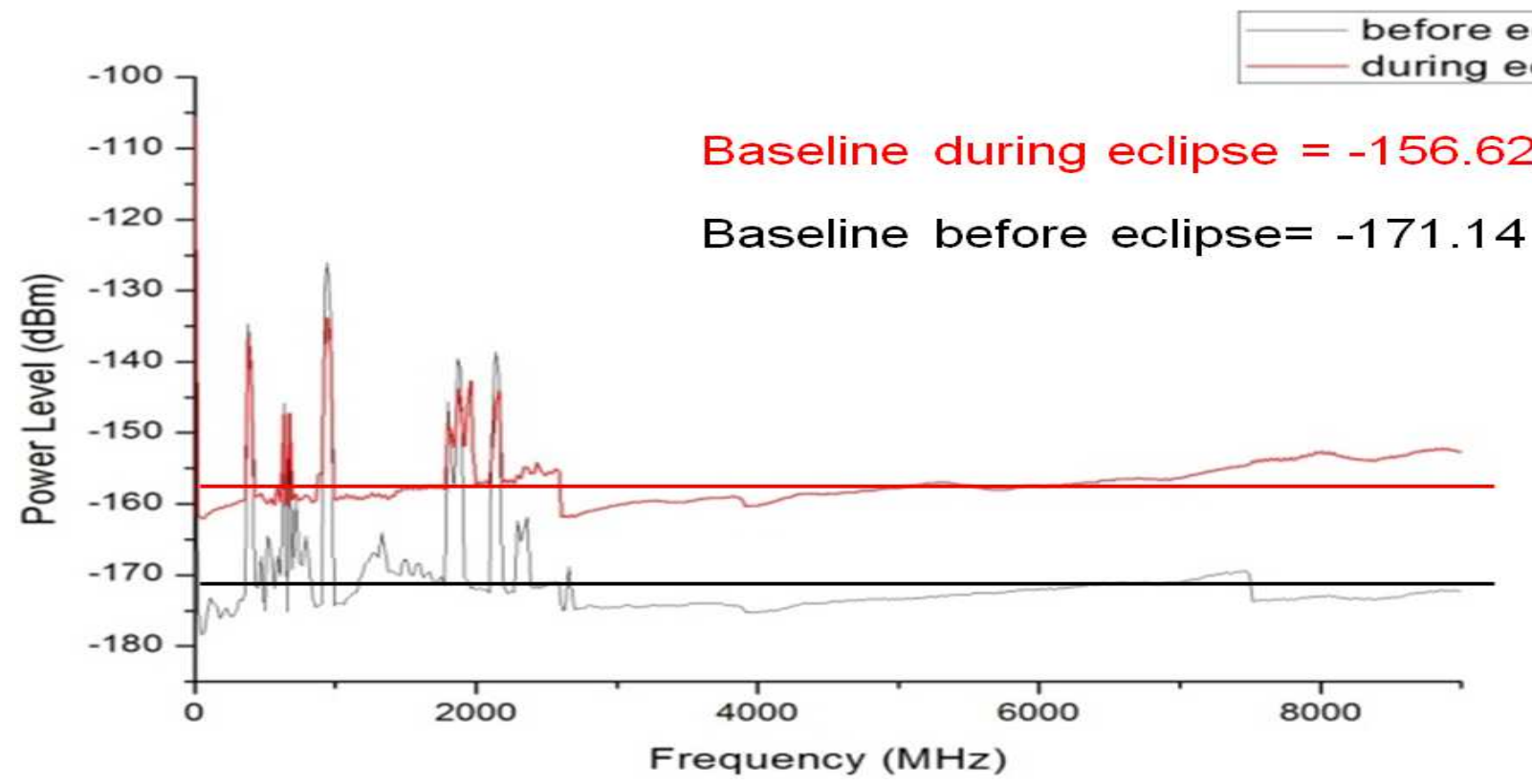

Fig. 5 The graph of frequency against the power levels with their baseline for two observations 
TABLE IIIII

The Description of Prominence PEAKS AND TheIr SOURCES FOR BEFORE SOLAR ECLIPSE

\begin{tabular}{|l|l|}
\hline Frequency (MHz) & Sources \\
\hline 382.5 & Digital Trunked Radio System \\
\hline 630 & $\begin{array}{l}\text { Analogue TV and Digital Terrestrial } \\
\text { Television including Terrestrial Sound } \\
\text { Broadcasting (Channel 41) }\end{array}$ \\
\hline 945 & $\begin{array}{l}\text { Cellular Mobile Service } \\
\text { ([EGSM/GSM]/IMT)(Celcom) }\end{array}$ \\
\hline 1327.5 & $\begin{array}{l}\text { Global System for Mobile 1800 (GSM } \\
\text { 1800) Lower Band (Celcom) }\end{array}$ \\
\hline 1867.5 & $\begin{array}{l}\text { Global System for Mobile 1800 (GSM } \\
1800) \text { Upper Band (DiGi) }\end{array}$ \\
\hline 2127.5 & $\begin{array}{l}\text { International Mobile Telecomuniccation- } \\
\text { 2000(IMT 2000) Frequency Division } \\
\text { Duplex (FDD) Lower Band (maxis) }\end{array}$ \\
\hline 2362.5 & $\begin{array}{l}\text { International Mobile Telecomuniccation- } \\
\text { 2000(IMT 2000) Frequency Division } \\
\text { Duplex (FDD) Upper Band (DiGi) }\end{array}$ \\
\hline
\end{tabular}

TABLE IVV

THE DESCRIPTION OF PROMINENCE PEAKS AND THEIR SOURCES FOR DURING SOLAR ECLIPSE

\begin{tabular}{|l|l|}
\hline $\begin{array}{l}\text { Frequency } \\
\text { (MHz) }\end{array}$ & Sources \\
\hline 382.5 & Digital Trunked Radio System \\
\hline 675 & $\begin{array}{l}\text { Analogue TV and Digital Terrestial Television } \\
\text { including Terrestial Sound Broadcasting } \\
\text { (Channel 46) }\end{array}$ \\
\hline 945 & $\begin{array}{l}\text { Cellular Mobile Service } \\
\text { ([EGSM/GSM]/IMT)(Celcom) }\end{array}$ \\
\hline 1957.5 & $\begin{array}{l}\text { International Mobile Telecomuniccation-2000 } \\
\text { (IMT 2000) Frequency Division Duplex (FDD) } \\
\text { Lower Band (DiGi) }\end{array}$ \\
\hline 2160 & $\begin{array}{l}\text { International Mobile Telecomuniccation-2000 } \\
\text { (IMT 2000) Frequency Division Duplex (FDD) } \\
\text { Upper Band (DiGi) }\end{array}$ \\
\hline
\end{tabular}

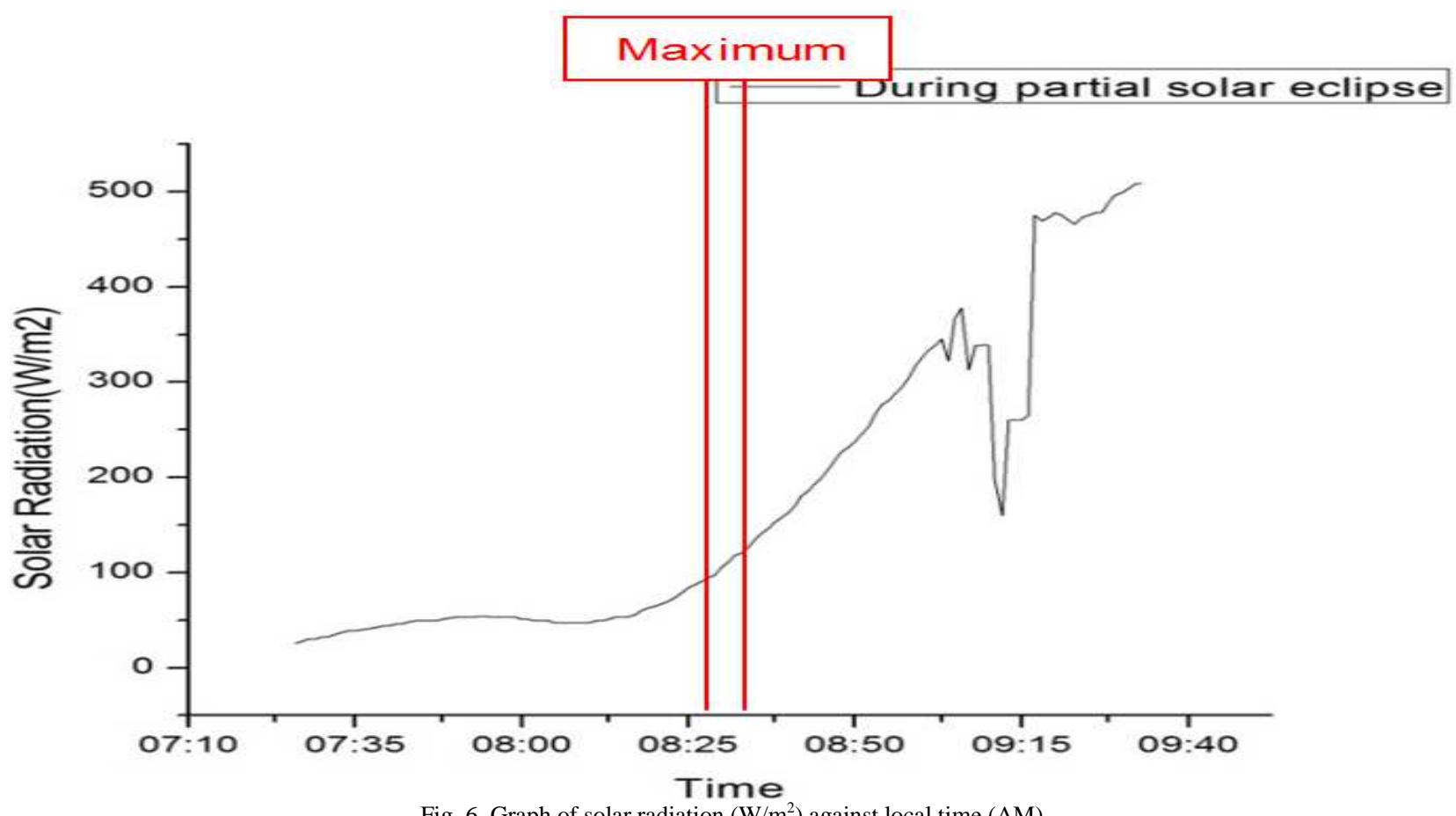

Fig. 6 Graph of solar radiation $\left(\mathrm{W} / \mathrm{m}^{2}\right)$ against local time (AM)

The decreasing the number of peak signal before and during the solar eclipse was clearly reduced from seven into five peaks. And the width of each peak signal during the solar eclipse also is not wide as before solar eclipse. The clear radio frequency has been considered as an RFI-free frequency window by [11].

\section{B. Solar Radiation}

The solar radiation was recorded by Weather Station and plotted as following Fig. 6. The measurement of solar radiation was increasing following the time.

During the maximum of the partial solar eclipse, the solar radiation is increasing with normal rate. However, start from 9:11 am until 9:16 am, the solar radiation was decreased by more than $50 \%$. This is because maybe the cloud was blocked the solar sensor at the instrument. Then, solar radiation was continuously increased at the time.

\section{Solar Activities}

In the other hand, NOAA report that the solar flare type C occurred at 13:03 UTC, 8th March 2016 observed by their spacecraft as Fig. 7 (b). This type of solar flare continues to emit from Active Region 12511 (AR12511) and does not produce any solar radio burst.

It can be concluded that the solar radio burst was impossible to occur at the same time and date of the solar eclipse. This is because solar radio burst was associated with a huge of solar flare and CME during active solar cycle [12]. In addition, the year of 2016 is the minimum of 24th of solar cycle as referring to NOAA, so that the number occurrence of radio burst [15] and sunspots was decreasing. 


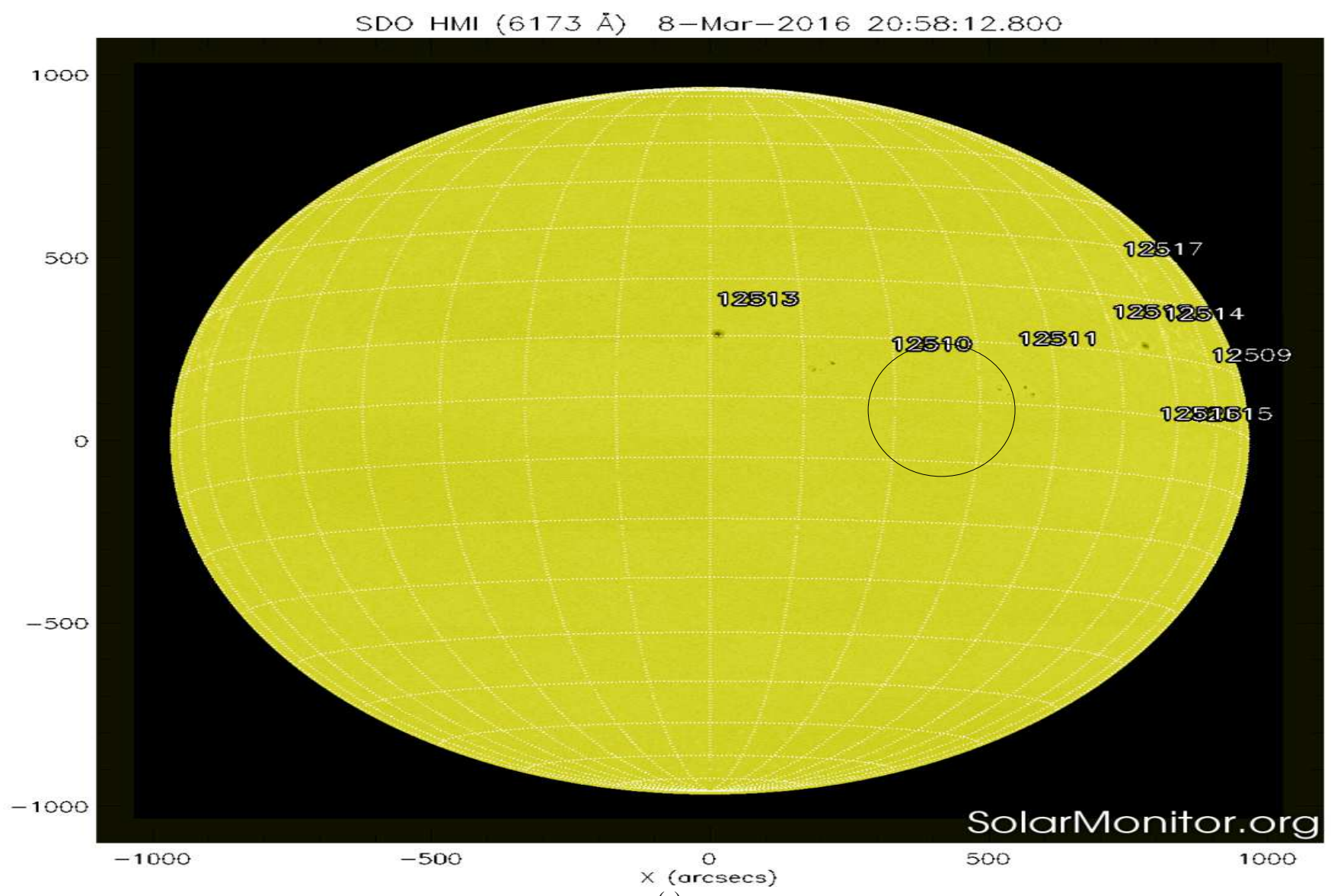

(a)

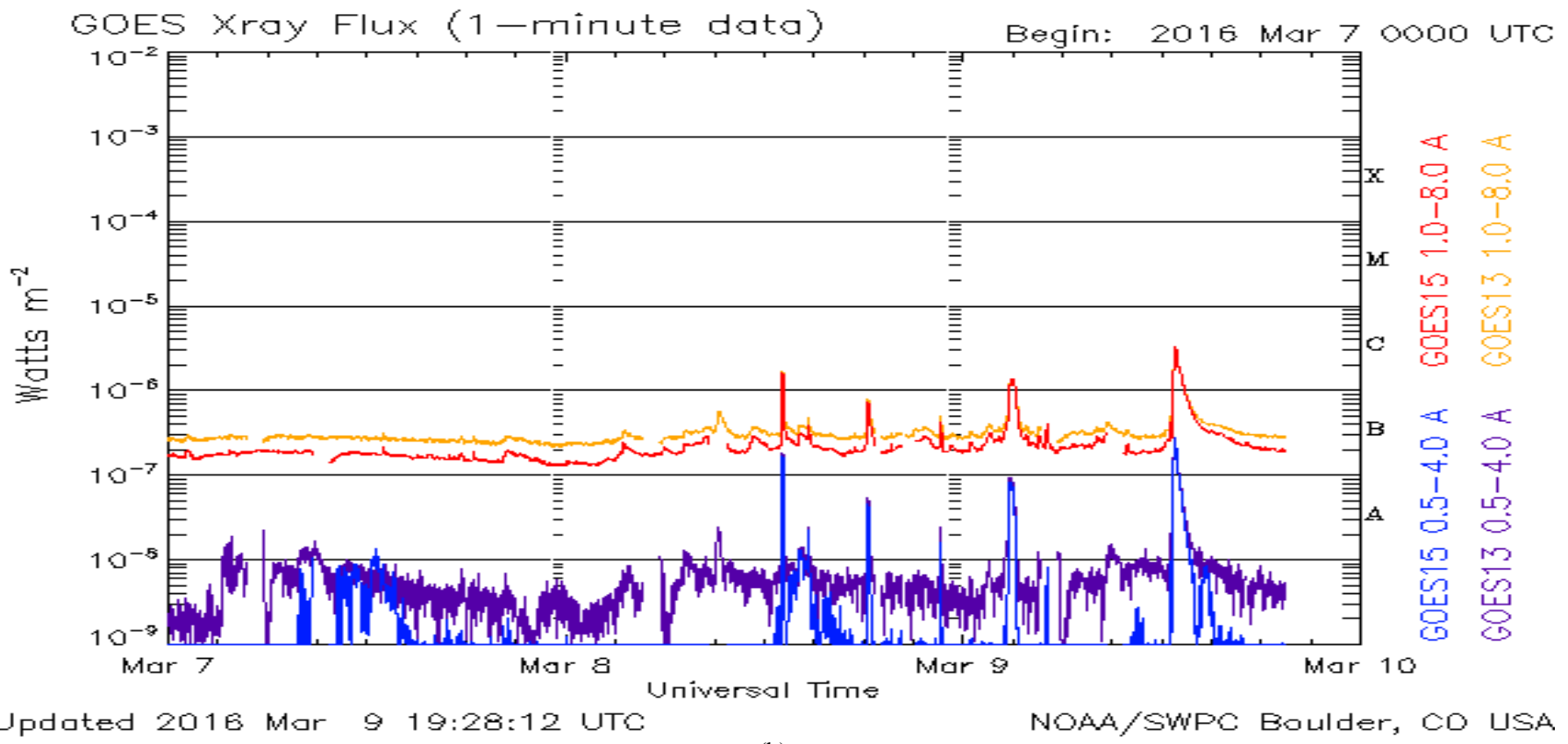

(b)

Fig. 7 a) The active region 12511(AR12511) located on the Sun at 8th March 2016 (dark circle) and b) GOES mission recorded x-ray flux data from 7th until 10th March 2016

\section{CONCLUSION}

Malaysia is one of the countries that have experienced a partial solar eclipse on 9th March 2016 with about $67 \%$ until $80 \%$ the Moon covered the Sun. As observation conducted on that day at Balai Cerap KUSZA, Merang, Terengganu found that this phenomenon is not enough proving to give an effect of the radio signal and solar radiation. Although the baseline of radio signal [14] before $(-171.14 \mathrm{dBm})$ and after $(-156.62 \mathrm{dBm})$ of the partial solar eclipse on 9th March 2016 showed the difference result about $14.52 \mathrm{dBm}$, and the number of prominence peaks also decreased from 7 peaks to 5 peaks during the partial solar eclipse, yet, it was still unable to prove in a scientific result. 
In addition, insignificant prove of solar radiation are shows from the changes of solar radiation before and during the maximum of the partial solar eclipse. This result may not affect due to less percentage of Moon covered the Malaysia during a partial solar eclipse. Also, active regions and solar flares taken by the NOAA space mission shows they are not facing the Earth directly.

Even though, this work is a part of an initial survey for partial solar eclipse in Malaysia. It is hoped that the radio signal observation and others parameters that can be affected from solar eclipse will continue. It should be noted that the solar eclipse may affect other factors. It is also hoped that this work can contribute the initial investigation toward partial solar eclipse.

\section{ACKNOWLEDGMENT}

This study was supported by several university grants such as RACE-UNISZA (RACE/F1/ST1/UNISZA/15), RACE-UM (CR008-2015), FRGS (FRGS/1/2015/SG02 /UNISZA/02/1), UMT (68006/INSENTIF/60) and UMT $(68006 / 2016 / 79)$. The authors are thankful to the teams of Electromagnetics Research Group (EMRG) Malaysia, East Coast Environmental Research Institute (ESERI) and National Space Agency for sharing their image and knowledge of solar eclipse. Also, we are grateful to NOAA for its data online.

\section{REFERENCES}

[1] X. Wang and Y. H. Yan, "Analysis of the CME-driven shock from the SEP event that occurred on 2006 December 14," Research in Astronomy and Astrophysics, vol. 12, pp. 1535-1541, Nov. 2012.

[2] J. M. Pasachoff, "Scientific observations at total solar eclipses," Research in Astronomy and Astrophysics, vol. 9, pp. 613-636, Jun. 2009.

[3] S. Aizam. (2016) Risalah falak edisi 22016 on Muftiselangor.gov.my. [Online]. Available: http://www.muftiselangor.gov.my/ms/falak-syarie/15-kandungandinamik/pengumuman/480-risalah-falak-edisi-2-2016
[4] C. Frohlich and J. Lean, "The Sun's total irradiance: Cycles, trends and related climate change uncertainties since 1976," Geophysical Research Letters, vol. 25, pp. 4377-4380, Dec. 1998.

[5] W. D. Pesnell, Solar Dynamics Observatory (SDO), Cham, Switzerland: Springer International Publishing, 2015.

[6] K. J. W. Lynn, "The total solar eclipse of 23 October 1976 observed at VLF," Journal of Atmospheric and Terrestrial Physics, vol. 43, pp. 1309-1316, Dec. 1981.

[7] A. Mendes da Costa, N. M. Paes Leme, and L. Rizzo Piazza, "Lower ionosphere effect observed during the 30 June 1992 total solar eclipse," Journal of Atmospheric and Terrestrial Physics, vol. 57, pp. 13-17, Jan. 1995.

[8] Z. S. Hamidi, N. N. M. Shariff, and C. Monstein, "Scenario of solar radio burst type III during solar eclipse on 14th November 2012," International Letters of Chemistry, Physics and Astronomy, vol. 13, pp. 135-14, Jul. 2014.

[9] B. Vogel, M. Baldauf, and F. Fiedler, "The influence of a solar eclipse on temperature and wind in the upper Rhine valley-A numerical case study," Meteorologische Zeitschrift, vol. 10, pp. 207214, May 2001.

[10] K. L. Aplin and R. G. Harrison, "Meteorological effects of the eclipse of 11th August 1999 in cloudy and clear conditions," Proceedings of the Royal Society of London A: Mathematical, Physical and Engineering Sciences, vol. 459, pp. 353-371, Feb. 2003.

[11] Z. Z. Abidin, N. M. Anim, Z. S. Hamidi, C. Monstein, Z. A. Ibrahim, R. Umar, N.N.M. Shariff, N. Ramli, N.A.I. Aziz, and I. Sukma, "Radio frequency interference in solar monitoring using CALliStO," New Astronomy Reviews, vol. 67, pp. 18-33, Aug. 2015.

[12] N. Ramli, Z. S. Hamidi, Z. Z. Abidin, and S. N. Shahar, "The relation between solar radio burst types II, III and IV due to solar activities," in Proc. IEEE IconSpace'15, 2015, p. 123.

[13] S. N. U. Sabri, N. H. Zainol, M. O. Ali, N. N. M. Shariff, N. Hussien, M. S. Faid, Z. S. Hamidi, and C. Monstein, "The dependence of log periodic dipole antenna (LPDA) and e-CALLISTO software to determine the type of solar radio burst (I-V)," in Proc. IEEE ICIMSA'16, 2016, p. 1.

[14] R. Mat, M. M. Shafie, S. Ahmad, R. Umar, Y. B. Seok, and N. H. Sabri, "Temperature effect on the tropospheric radio signal strength for UHF band at Terengganu, Malaysia," International Journal on Advanced Science, Engineering and Information Technology, vol. 6, pp. 770-774, Oct. 2016.

[15] N. Z. M. Afandi, Z. Z. Abidin, R. Umar, N. H. Sabri, Z. A. Ibrahim, and C. Monstein, "Implementation of frequency drift for identification of solar radio burst type II," International Journal on Advanced Science, Engineering and Information Technology, vol. 6, pp. 775-780, Oct. 2016. 